\title{
Desenvolvimento de Novilhas de Corte Submetidas a Diferentes Sistemas Alimentares
}

\author{
Marta Gomes da Rocha ${ }^{1}$, Alcides Pilau², Davi Teixeira dos Santos ${ }^{3}$, Denise Baptaglin \\ Montagner ${ }^{4}$, Fabiana Kellermann de Freitas $^{5}$, Caius Barcellos de Pellegrini ${ }^{6}$
}

\begin{abstract}
RESUMO - Foi avaliado o efeito de sistemas alimentares sobre o desenvolvimento de fêmeas de corte, dos oito aos 18/20 meses de idade. Foram avaliadas novilhas da raça Charolês e suas cruzas com Nelore. Os sistemas de alimentação foram: 'aveia + azevém + milheto' - pastagem de aveia preta (Avena strigosa Schreb) e azevém (Lolium multiflorum Lam), seguida de pastagem de milheto (Pennisetum americanum (L.) Leeke); ‘aveia + azevém + campo’ - pastagem de aveia e azevém mais campo nativo ocupado por capim Annoni (Eragrostis planna Nees); ‘aveia + azevém + suplementação + milheto’ - pastagem de aveia preta e azevém com suplementação energética mais pastagem de milheto; ‘aveia + azevém + suplementação + campo’- pastagem de aveia preta e azevém com suplementação mais campo nativo ocupado por capim Annoni. O suplemento foi grão de sorgo moído, 0,7\% do peso vivo (PV)/dia. Foram tomados registros de PV, escore de condição corporal (ECC), atividade ovariana e manifestação de estro no período dos 18 aos 20 meses de idade das novilhas. Novilhas exclusivamente em pastagem natural durante o verão/outono não atingiram o peso recomendado para acasalamento aos 18/20 meses de idade. Novilhas que apresentaram estro foram mais pesadas e realizaram maior ganho diário médio durante o inverno. Novilhas mantidas em aveia + azevém + milheto apresentaram maior porcentagem de ovários funcionais aos 18/20 meses de idade.
\end{abstract}

Palavras-chave: acasalamento aos 18-20 meses, aveia, azevém, milheto, sistemas de produção

\section{Performance of Beef Heifers Submitted at Different Feeding Systems}

ABSTRACT - The effect of feeding systems on performance of beef heifers, on period of eight to 18/20 months of age. Charolais heifers and their crosses with Nellore were evaluated. The feeding systems were: 'Oat + Annual ryegrass + Pearl millet'- Black oat (Avena strigosa Schreb) and Annual ryegrass (Lolium multiflorum Lam) and Pearl millet (Pennisetum americanum (L.) Leeke) pasture; 'Oat + Annual ryegrass + natural pasture'- Black oat and annual ryegrass and natural pasture with Annoni grass (Eragrostis planna Nees); 'Oat + Annual ryegrass + supplementation + pearl millet'- Black oat and Annual ryegrass with supplementation and Pearl millet pasture; 'Oat + Annual ryegrass + supplementation + natural pasture’- Black oat and Annual ryegrass with supplementation and natural pasture with Annoni grass. The supplement utilized was ground sorghum on $0.7 \%$ of the live weight/day. Live weight, condition score, ovarian activity and number of heifers showing heat on period of 18 to 20 months of age were recorded. Heifers kept only in natural pasture during summer/autumn did not achieve recommended live weight for mating at 18/20 months of age. Heifers cicling were heavier and had greater average daily gain in winter. Heifers kept on Oat + Annual ryegrass + Pearl millet had greater ovarian activity at 18/20 months of age.

Key Words: annual ryegrass, black oat, mating at 18/20 months of age, pearl millet, production systems

\section{Introdução}

No Rio Grande do Sul, em muitos sistemas de produção de pecuária de corte, a idade de 24 meses é utilizada como critério para submeter as fêmeas à reprodução pela primeira vez. Com esta prática são atingidos bons índices de prenhez, mas baixos índices de repetição de cria em vacas primíparas, com cria ao pé, em campo nativo. Um desafio nos sistemas criatórios é reduzir esta idade de acasalamento. Existe potencial biológico para que as fêmeas sejam acasaladas aos 14 meses de idade, mas este sistema, por ser muito exigente em alimentação suplementar para os animais, não estimula sua adoção. A dificuldade é atender, em campo nativo, as exigências para crescimento, lactação e reconcepção da novilha primípara aos dois anos. Um sistema alternativo de produção seria o acasalamento de fêmeas de corte aos 18 meses de idade. Neste sistema, as vacas jovens poderiam ser desmamadas, em tempo hábil

\footnotetext{
${ }^{1}$ Eng. Agr. Dra. Profa. Adj -Departamento de Zootecnia - UFSM. Tuiuti, 1554/201. Santa Maria. RS (tata@pro.via-rs.com.br).

2 Zoot. Aluno do curso de Pós-Graduação em Zootecnia- UFSM. Bolsista CAPES (alcidespilau@bol.com.br).

3 Zoot. Aluno do curso de Pós-Graduação em Zootecnia- UFSM. Bolsista CAPES (daviteixeira@hotmail.com).

${ }^{4}$ Zoot. Aluno do curso de Pós-Graduação em Zootecnia- UFSM. Bolsista CNPq (demontagner@yahoo.com.br).

${ }^{5}$ Eng. Agron. Aluno do curso de Pós-Graduação em Zootecnia- UFSM (fkfreitas@mail.ufsm.br)

${ }^{6}$ Estudante do curso de graduação em Zootecnia - UFSM
} 
para recomposição da condição corporal e manifestação de estro, antes da estação de monta primaveril subseqüente ao parto. Esta seria uma vantagem, com relação ao sistema 'dois anos', pois permitiria a obtenção de maiores taxas de prenhez no segundo acasalamento. Este sistema apresentaria ainda como vantagens o maior aproveitamento da vida útil da fêmea, maior número de terneiros, redução de áreas e custos na recria de fêmeas de reposição e diminuição de custos com maior aproveitamento da mão-de-obra (Hill, 1995; Semmelmann et al., 2001).

É importante que as novilhas alcancem a puberdade e o acasalamento o mais cedo possível, para melhorar a eficiência biológica do rebanho (Lanna, 1997). Idade à puberdade em fêmeas é uma característica importante em gado de corte, à medida que o sistema de produção se torna mais intensivo e competitivo (Restle et al., 1999). A redução da idade de acasalamento de fêmeas leva a uma alteração na estrutura do rebanho de cria, reduzindo o intervalo entre gerações e diminuindo a participação de animais improdutivos na composição do rebanho (Albuquerque \& Fries, 1997). No Rio Grande do Sul, o rebanho de corte é constituído por 13.467 .665 cabeças. Fêmeas em recria, de um a dois e de dois a três anos de idade, são aproximadamente 2.571.704 cabeças, representando 18,96\% do rebanho gaúcho (Anualpec, 2002).

A base alimentar do rebanho de cria no estado é a pastagem natural, que diminui sua produção e reduz sua qualidade no outono e inverno. Para permitir que as fêmeas atinjam desenvolvimento satisfatório, 65\% do peso adulto aos dois anos de idade, e assegurar um aporte contínuo de nutrientes para os animais em recria, são utilizadas pastagens cultivadas de inverno (Beretta \& Lobato, 1996; Pereira Netto \& Lobato, 1998). O uso estratégico de suplementos acelera o crescimento de fêmeas no período pós-desmama (Rocha \& Lobato, 2002a). A suplementação energética para recria de fêmeas interfere de forma positiva no seu ganho médio diário, no escore de condição corporal e na taxa de aparecimento de cio antes dos 12 meses de idade (Frizzo et al., 2003).

Considerando indispensável o uso de pastagens cultivadas no primeiro inverno, seria necessário testar a viabilidade do uso exclusivo de pastagem natural, durante o período estival subseqüente, visando obter desenvolvimento animal adequado para acasalamento de novilhas aos 18-20 meses. Grande parte dos campos naturais no estado, no entanto, estão infestados por capim Annoni (Eragrostis planna Nees). Esta espécie é de baixa qualidade, mesmo no período de primavera e verão.

O Rio Grande do Sul apresenta condição privilegiada de produção de forragem, pois, além do cultivo de espécies temperadas, de excelente qualidade, existe a possibilidade de utilização de um grande número de espécies tropicais de elevado potencial de produção. O milheto (Pennisetum americanum (L) Leeke) é caracterizado por alta produção e boa qualidade nos períodos mais quentes do ano (Moraes \& Maraschin, 1988).

Para gerar informações sobre sistemas alimentares para a recria de fêmeas de corte, objetivou-se, com este trabalho, avaliar o desenvolvimento corporal e aparecimento de estros em novilhas submetidas a diferentes estratégias de alimentação, dos 8 aos 20 meses de idade. Os sistemas alimentares utilizados envolveram o uso de pastagens cultivadas anuais, aveia (Avena strigosa Schreb), azevém (Lolium multiflorum Lam); milheto (Pennisetum americanum (L) Leeke), campo natural ocupado por capim Annoni e suplementação energética.

\section{Material e Métodos}

O experimento foi conduzido em Santa Maria, Rio Grande do Sul, em área pertencente ao Departamento de Zootecnia da Universidade Federal de Santa MariaUFSM, situada na Depressão Central do estado, com altitude de 95 m acima do nível do mar, latitude 29² $43^{\prime}$ Sul e longitude $53^{\circ} 42^{\prime}$ ' Oeste. O clima da região é Cfa (subtropical úmido) conforme classificação de Köppen (Moreno, 1961).

Foram utilizadas 80 novilhas de corte da raça Charolês e suas cruzas com Nelore, nascidas entre setembro e dezembro de 2000. Os animais foram identificados por tatuagem, ao nascimento, e brinco plástico durante o período experimental.

A área experimental foi assim constituída: no inverno, 17 ha de aveia (A. strigosa Schreb) + azevém (L. multiflorum Lam); no verão, 07 ha de milheto (P. americanum (L) Leeke) e 31,36 ha de pastagem natural, ocupada por capim Annoni (E. planna Nees). No inverno, bezerras suplementadas e não-suplementadas permaneceram em potreiros distintos da mesma pastagem, com massa de forragem similar.

As bezerras foram submetidas a quatro sistemas alimentares, conduzidos de julho de 2001 a junho de 2002. Os sistemas foram os seguintes: 
'Aveia + azevém + milheto': bezerras em pastagem de aveia preta (A. strigosa Schreb) e azevém (L. multiflorum Lam), seguido de pastagem de milheto (P. americanum (L.) Leeke);

'Aveia + azevém + campo': bezerras em pastagem de aveia preta (A. strigosa Schreb) e azevém (L. multiflorum Lam), seguido de campo nativo ocupado por capim Annoni (E. planna Nees);

'Aveia + azevém + suplementação + milheto': bezerras em pastagem de aveia (A. strigosa Schreb) e azevém (L. multiflorum Lam) com suplementação energética, seguido de pastagem de milheto;

'Aveia + azevém + suplementação + campo': bezerras em pastagem de aveia preta (A. strigosa Schreb) e azevém (L. multiflorum Lam) com suplementação energética, seguido de campo nativo ocupado por capim-Annoni (E. planna Nees).

O período de pastejo, em aveia + azevém, foi de 132 dias (01/07 a 09/11/2001). A pastagem foi conduzida com massa de forragem média de $1300 \mathrm{~kg} /$ ha de matéria seca (MS), com oferta de $10 \mathrm{~kg}$ de MS por $100 \mathrm{~kg}$ de peso vivo (PV). O sistema de pastejo foi contínuo, com taxa de lotação variável. A carga animal média foi de $910 \mathrm{~kg} / \mathrm{ha}$ de PV. O período de pastejo no milheto foi de 99 dias (26/12 a 04/04/2002). A pastagem de milheto foi manejada com massa de forragem média de $1.300 \mathrm{~kg} / \mathrm{ha}$ de MS, carga animal média de $2.700 \mathrm{~kg} / \mathrm{ha}$ de PV, oferta de $9 \mathrm{~kg}$ de MS por $100 \mathrm{~kg}$ de PV. A massa de forragem média, na pastagem natural ocupada com capim Annoni, foi de $3.000 \mathrm{~kg} /$ ha de MS. A área foi de 31,36 ha, com carga animal média de $300 \mathrm{~kg} /$ ha de PV. Durante o período de utilização da pastagem de inverno (01/07 a 09/11/ 2001), o suplemento utilizado foi grão de sorgo moído (6,5\% PB; 72\% NDT), na quantidade de $0,7 \%$ do PV, fornecido diariamente às $14 \mathrm{~h}$. A quantidade de suplemento oferecido foi regulada a cada três dias, conforme variação da carga animal.

Após o término das pastagens de aveia e azevém e de milheto, todos os animais permaneceram como um só grupo, em campo natural (10/11 a 25/12/2001 e 15/04 a 01/06/2002).

As estimativas da massa de forragem foram feitas pelo método de dupla amostragem, descrito por Gardner (1986). A partir dos valores de carga animal e taxa de acúmulo de forragem, foram determinados, nas espécies cultivadas, os valores de oferta de forragem, em kg de MS/100 kg de PV. A determinação dos teores de proteína bruta (AOAC, 1984) e digestibilidade in vitro da matéria seca (Tilley \& Terry, 1963) foi realizada pela análise laboratorial de amostras de forragem colhidas por meio de simulação de pastejo, conforme a técnica descrita por Euclides et al. (1992).

As pesagens dos animais foram realizadas a cada 28 dias após jejum prévio de 12 horas. Em cada pesagem, as novilhas foram submetidas a avaliações de escore de condição corporal (ECC), por dois avaliadores treinados, utilizando-se uma escala de um a cinco pontos, conforme metodologia adaptada de Lowman et al. (1976).

As avaliações do aparelho reprodutivo das novilhas foram realizadas mediante palpação retal, em duas datas (09/11/2001 e 01/06/2002), quando foi verificada a sua funcionalidade (tamanho de ovário e presença de corpo lúteo). As observações de estro foram realizadas por 48 dias (14/04 a 01/06/2002), por dois observadores, em dois turnos por dia, no início da manhã e final da tarde.

O delineamento experimental foi o inteiramente casualizado, sendo os animais considerados como repetições. O modelo matemático referente à análise dos parâmetros estimados foi representado por:

$$
\mathrm{Y}_{\mathrm{ijk}}=\mu+\mathrm{S}_{\mathrm{i}}+\mathrm{P}_{\mathrm{j}}+\mathrm{R}_{\mathrm{k}}(\mathrm{S})_{\mathrm{i}}+(\mathrm{S} * \mathrm{P})_{\mathrm{ij}}+\mathrm{e}_{\mathrm{ijk}}
$$

em que $Y_{i j k}=$ variáveis dependentes; $\mu$ = média de todas as observações; $S_{i}=$ efeito do i-ésimo sistema alimentar; $\mathrm{P}_{\mathrm{j}}=$ efeito do j-ésimo período; $\mathrm{R}_{\mathrm{k}}(\mathrm{S})_{\mathrm{i}}=$ efeito da k-ésima repetição dentro do i-ésimo sistema alimentar (erro A); $\mathrm{S}^{*} \mathrm{P}_{\mathrm{ij}}=$ efeito de interação entre o i-ésimo sistema alimentar e o j-ésimo período; $\mathrm{e}_{\mathrm{ijk}}=$ erro experimental (erro B).

As variáveis estudadas foram submetidas à análise de variância dos dados e teste F a 5\% de significância. Quando foram detectadas diferenças entre sistemas alimentares ou períodos, foram realizados testes de comparação de médias (5\% de significância). Em caso de interação $S^{*} P$, foi realizado teste de regressão polinomial até terceira ordem, a 5\% de significância, sendo considerada a equação de maior coeficiente de determinação $\left(\mathrm{R}^{2}\right)$. As análises foram efetuadas utilizando-se o procedimento GLM (General Linear Models) do programa estatístico SAS versão 6.08 (SAS, 1996).

A análise estatística do efeito dos tratamentos no aparecimento de estro foi feita pelo teste de aleatorização, utilizando-se o programa MULTIV, a 10\% de significância. 


\section{Resultados e Discussão}

As medidas iniciais de peso vivo e condição corporal não diferiram $(\mathrm{P}>0,05)$ entre os sistemas avaliados. Por ocasião da entrada na pastagem de inverno, os animais apresentavam, em média, PV de 167,4 kg e ECC de 2,74.

Houve interação significativa $(\mathrm{P}<0,05)$ entre sistema alimentar e período para a variável ganho diário médio. Na Figura 1, são apresentados os valores de GDM observados e ajustados pelas equações de regressão. O maior GDM foi observado em animais sob pastagem de aveia e azevém, sem diferir $(\mathrm{P}>0,05)$ entre animais recebendo suplementação energética ou exclusivamente em pastagem.

No período de 09/11 a 25/12, bezerras oriundas de ‘aveia + azevém’ e 'aveia + azevém + suplemento' foram alocadas em um único lote, em campo nativo; nesta ocasião, os animais perderam peso. Beretta \& Lobato (1998) e Rocha \& Lobato (2002b) também observaram que os ganhos realizados por bovinos, em pastagem, no período de primavera, estiveram relacionados de forma inversa, com ganhos realizados no período de inverno. Novilhas que expressam o

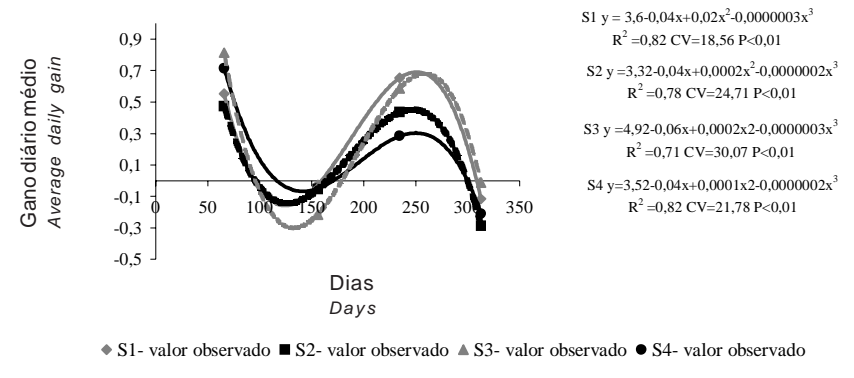

Figura 1 - Estimativas do ganho diário médio ( $\mathrm{kg} / \mathrm{dia})$ de bezerras de corte em quatro sistemas alimentares (S1- 'aveia + azevém + milheto'; S2- 'aveia + azevém + campo'; S3- 'aveia + azevém + suplementação + milheto'; S4- 'aveia + azevém + suplementação + campo').

Figure 1 - Estimates for liveweight daily gain of beef heifers in four feeding systems (S1-Oat + Annual ryegrass + Pearl millet pasture; S2- Oat + Annual ryegrass + natural pasture; S3- Oat + Annual ryegrass + supplementation + Pearl millet ; S4- Oat + Annual ryegrass + supplementation + natural pasture). máximo potencial genético para ganho de peso no período pós-desmama apresentam menor GDM quando submetidas à restrição alimentar em períodos subseqüentes (Allden, 1981).

O milheto foi capaz de proporcionar GDM de 0,814 kg, embora Moraes \& Maraschin (1988) relatem ganhos em torno de 1,0 kg para novilhos em pastejo nesta mesma espécie. O ganho observado no presente experimento deve-se, provavelmente, à época tardia de utilização do milheto (26/12 a 14/04), pois esta é uma espécie de dias longos e, nos dias curtos de outono, entra em fase reprodutiva, com menor proporção folha/caule e altos níveis de constituintes da parede celular na fase final de utilização. Na mesma ocasião, para animais em campo nativo, o GDM foi de 0,359 kg. Este ganho ficou aquém do potencial de ganho em pastagem nativa, na Depressão Central do Rio Grande do Sul, de 0,500 kg (Moojen \& Maraschin, 2002). Por outro lado, Pereira Netto \& Lobato (1998) relataram GDM de 0,246 kg, para novilhas de sobreano, em pastagem natural.

Na Tabela 1, são expressos os valores de massa de forragem, porcentagem de proteína bruta e digestibilidade in vitro da matéria orgânica das pastagens cultivadas. Em função das ofertas de forragem obtidas, 10 e $9 \mathrm{~kg}$ de MS por $100 \mathrm{~kg}$ de PV, para aveia + azevém e milheto, respectivamente, provavelmente não tenha existido restrição à seletividade, garantindo a possibilidade de consumo máximo de matéria seca pelos animais em pastejo. Em função das dimensões da área e dificuldades para realização da simulação de pastejo em campo infestado com Annoni, os dados de PB e DIVMO, neste sistema alimentar, são do material verde seco da massa de forragem (6,5 e 33,3\%, respectivamente). Nas pastagens cultivadas, a energia da forragem consumida foi, provavelmente, limitante para que os animais realizassem ganhos mais elevados, uma vez que os teores de PB estiveram acima das exigências para os ganhos realizados (NRC, 1984).

Em pastagem nativa, após a pastagem de milheto, os animais que haviam sido suplementados no inverno praticamente mantiveram peso $(\mathrm{GDM}=0,001 \mathrm{~kg})$, enquanto houve perda de peso nos animais de todos os outros sistemas, e esta perda variou de -0,134, em ‘aveia + azevém + milheto', a -0,275, em 'aveia + azevém + campo', sem diferença $(\mathrm{P}>0,05)$ entre elas. Também Moojen \& Maraschin (2002) relataram valores semelhantes de perda de peso de animais em pastagem nativa, durante o outono/inverno.

R. Bras. Zootec., v.33, n.6, p.2123-2131, 2004 (Supl. 2) 
Tabela 1 - Valores da massa de forragem (MF), conteúdo de proteína bruta (PB) e digestibilidade in vitro da matéria orgânica (DIVMO) das amostras da simulação manual de pastejo

Table 1 - Forage mass (FM), crude protein (CP) value and in vitro organic matter digestibility (IVOMD) of forage samples from pasture hand plucking

\begin{tabular}{|c|c|c|c|c|c|c|}
\hline \multirow{4}{*}{$\begin{array}{l}\text { Períodos } \\
\text { Periods }\end{array}$} & \multicolumn{6}{|c|}{$\begin{array}{c}\text { Pastagens } \\
\text { Pasture }\end{array}$} \\
\hline & \multicolumn{3}{|c|}{$\begin{array}{c}\text { Aveia + Azevém } \\
\text { Oat plus annual ryegrass }\end{array}$} & \multicolumn{3}{|c|}{$\begin{array}{c}\text { Milheto } \\
\text { Pearl millet }\end{array}$} \\
\hline & \multicolumn{6}{|c|}{$\begin{array}{l}\text { Parâmetros } \\
\text { Parameters }\end{array}$} \\
\hline & MF (kg/ha) & PB (\%) & DIVMO(\%) & MF (kg/ha) & PB(\%) & DIVMO(\%) \\
\hline & $F M$ & $C P$ & IVDOM & $F M$ & $C P$ & $I V D O M$ \\
\hline 01/07-08/11/2001 & 1310 & 18,65 & 65,00 & & & \\
\hline 26/12/2001-15/04/2002 & & & & 1270 & 15,17 & 57,79 \\
\hline
\end{tabular}

Para o parâmetro peso vivo, houve interação $(\mathrm{P}<0,05)$ entre sistema alimentar e período. Na Figura 2, são apresentados os valores observados e estimados, pelas equações de regressão ajustadas, do PV, em kg, nos quatro sistemas alimentares. Os PV médios, em 01/06, foram de 299, 260, 333 e 286, para 'aveia + azevém + milheto'; 'aveia + azevém + campo'; 'aveia + azevém + suplementação + milheto’ e 'aveia + azevém + suplementação + campo', respectivamente. Na data final de avaliação, a diferença foi de $73 \mathrm{~kg}$ entre o maior (333 kg; aveia + azevém + suplementação + milheto) e o menor peso médio (260 kg; aveia + azevém + campo).

Animais suplementados no inverno e mantidos em milheto no verão apresentaram, aos 18 meses, peso vivo superior $(\mathrm{P}<0,05)$ ao obtido por novilhas não-suplementadas no inverno e mantidas em campo nativo no verão. Animais dos demais sistemas apresentaram pesos intermediários, sem diferir $(\mathrm{P}>0,05)$ dos sistemas anteriores. $\mathrm{O}$ uso de pastagem natural infestada com Annoni, durante o verão, independentemente dos animais terem ou não recebido suplementação durante o inverno, não permitiu que as fêmeas atingissem, aos 20 meses de idade, $65 \%$ do seu peso adulto, avaliado em $292 \mathrm{~kg}$, considerado por Fox et al. (1988) como peso ótimo ao primeiro estro. O ganho realizado pelas novilhas não-suplementadas durante o inverno e exclusivamente em campo após este período fez com que seu peso aos 20 meses (260 kg) não diferisse $(\mathrm{P}>0,05)$ do seu peso ao final da pastagem de inverno, $228 \mathrm{~kg}$. Em novilhas provenientes do mesmo rebanho, Frizzo et al. (2003) observaram a primeira manifestação de estro aos $261 \mathrm{~kg}$ e 264 dias de idade. Pesos de 262,5 kg, aos 18 meses de idade, foram relatados por Semmelmann et al. (2001), em novilhas Nelore. Rocha \& Lobato (2002b), trabalhando com fêmeas Hereford e suas cruzas com Nelore, em diferentes sistemas alimentares na pósdesmama, observaram que, em média, o primeiro estro foi manifestado aos 14,6 meses de idade e $263 \mathrm{~kg}$ de peso vivo.

O ganho de peso realizado, durante o período experimental, 336 dias, foi de 132, 93, 166 e $119 \mathrm{~kg}$ para 'aveia + azevém + milheto'; 'aveia + azevém + campo'; 'aveia + azevém + suplementação + milheto' e 'aveia + azevém + suplementação + campo',

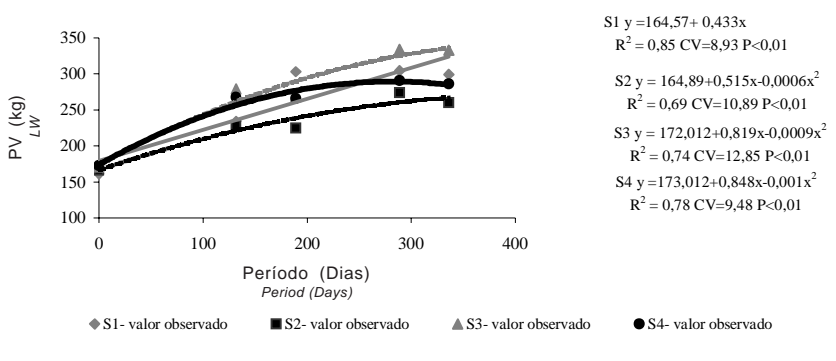

Figura 2 - Estimativas de peso vivo $(\mathrm{kg})$ de bezerras de corte em quatro sistemas alimentares (S1'aveia + azevém + milheto'; S2- 'aveia + azevém + campo'; S3-'aveia + azevém + suplementação + milheto'; S4- 'aveia + azevém + suplementação + campo').

Figure 2 - Estimates for liveweight $(\mathrm{kg})$ of beef heifers in four feeding systems (S1-Oat + Annual ryegrass + Pearl millet pasture; S2- Oat + Annual ryegrass + natural pasture; S3- Oat + Annual ryegrass + supplementation + Pearl millet pasture; S4- Oat + Annual ryegrass + supplementation + natural pasture). 
respectivamente. Considerando que bezerras para acasalamento aos 20 meses necessitam atingir, nesta ocasião, peso mínimo de 292 kg e que possuíam 167 kg (37\% do peso adulto), na entrada da pastagem de inverno, o ganho mínimo a realizar durante o período experimental seria de $125 \mathrm{~kg}$. Este ganho só foi realizado por animais que estiveram em pastagem de milheto. Semmelmann et al. (2001) observaram diferença média de 13,7 kg a favor das novilhas prenhes no sobreano, com taxa de prenhez média de 20,6\%.

Para ECC, houve interação $(\mathrm{P}<0,01)$ entre sistema alimentar e período. Na Figura 3, são apresentados os valores observados e estimados, pelas equações de regressão ajustadas, de escore de condição corporal (1-5), nos quatro sistemas alimentares.

Os maiores ECC $(\mathrm{P}<0,05)$ foram apresentados pelos animais suplementados, no período de inverno. Aos 20 meses, animais que estiveram em pastagem de milheto apresentaram ECC superior $(\mathrm{P}<0,05)$ aos animais provenientes dos sistemas com campo nativo e estes não diferiram entre si $(\mathrm{P}>0,05)$. Os ECC das novilhas, no término do experimento em 01/06, no entanto, independentemente dos sistemas, são todos inferiores a 3,0. A condição corporal de 3 (escala de 1-5) é considerada desejável, para novilhas de reposição, no período compreendido entre os três

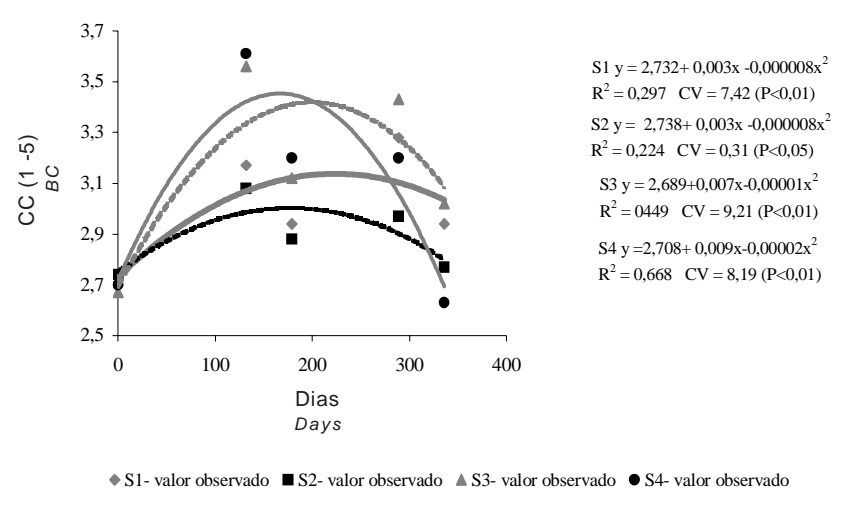

Figura 3 - Estimativas do escore de condição corporal (1-5) de bezerras de corte em quatro sistemas alimentares (S1-'aveia + azevém + milheto'; S2- 'aveia + azevém + campo'; S3- 'aveia + azevém + suplementação + milheto'; S4- 'aveia + azevém + suplementação + campo').

Figure 3 - Estimates for body condition score (1-5) of beef heifers in four feeding systems (S1-Oat + Annual ryegrass + Pearl millet; S2- Oat + Annual ryegrass + natural pasture; S3-Oat + Annual ryegrass + supplementation + Pearl millet; S4- Oat + Annual ryegrass + supplementation + natural pasture. meses de idade e o acasalamento (Noller, 1997). Novilhas que permaneceram em 'aveia + azevém + suplementação + campo’ apresentaram, no outono, ECC de 2,6, inferior ao ECC observado no início da utilização da pastagem de inverno, de 2,7. Para fêmeas acasaladas com um ano de idade, no início da estação de acasalamento, Beretta \& Lobato (1998) relataram ECC de 2,8 e Rocha \& Lobato (2002b), de 3,5 . A condição corporal, que permite avaliar subjetivamente a quantidade de tecido adiposo depositado, constitui um dos indicadores do estado nutricional que mais se associa com a porcentagem de prenhez (Rice, 1991).

Sistemas alimentares não determinaram diferença no percentual de estros $(\mathrm{P}>0,05)$ aos vinte meses de idade. Idade e peso das novilhas por ocasião do aparecimento do estro, durante a estação de acasalamento, de acordo com os sistemas alimentares, são apresentadas na Figura 4.

Animais que estiveram em pastagem de milheto, mais pesados, e no campo nativo, mais leves, apresentaram média de 48,48 e 22,62\% de estros, respectivamente. A importância do número de fêmeas em estro no início da estação de acasalamento reside na sua correlação com o número de fêmeas que se tornam prenhas durante a mesma estação (Short \& Bellows, 1971). O percentual de estros foi inferior aos $50 \%$ observados aos 18 meses, em fêmeas cruzadas Charolês/Nelore, e superior aos 28,6\% observados em novilhas puras Charolês e Nelore, do

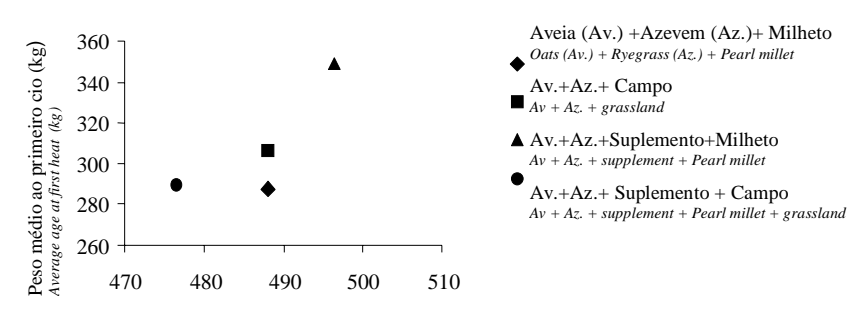

Idade média ao primeiro cio na estação de acasalamento aos 18/20 meses de idade (dias) Average age at first heat in mating season at 18/20 months of age (days)

Figura 4 - Idade e peso na manifestação de estro de novilhas de corte aos 18/20 meses de idade, quando submetidas a diferentes sistemas de alimentação.

Figure 4 - Average age and liveweight at heat in beef heifers at $18 / 20$ months of age under different feeding systems.

R. Bras. Zootec., v.33, n.6, p.2123-2131, 2004 (Supl. 2) 
mesmo rebanho (Restle et al., 1999). Observa-se, para a porcentagem de fêmeas em estro, um reflexo do padrão de peso vivo resultante dos sistemas alimentares (Figura 2).

Consta na Tabela 3 o resumo do desempenho geral das variáveis de peso vivo, condição corporal e GDM de novilhas com apresentação ou não de estro aos 20 meses.

Novilhas que apresentaram estro foram, em média, 27 e $42 \mathrm{~kg}$ mais pesadas $(\mathrm{P}<0,05)$ no final da pastagem de milheto e em 01/06, respectivamente. Esta observação confirma a validade da recomendação de Fox et al. (1988) sobre o peso alvo a ser atingido no início do acasalamento, já discutido anteriormente. Por outro lado, novilhas que apresentaram estro realizaram maior GDM $(\mathrm{P}<0,05), 0,770 \mathrm{~kg}$, no período correspondente à utilização da pastagem de inverno (01/07-08/11/2001). O fato de a interferência do ganho realizado nesta ocasião, no aparecimento de estros, estar possivelmente ligada apenas ao valor numérico ou à composição do ganho decorrente do uso da suplementação deve ser esclarecido em experimentos posteriores.

Em sistema de acasalamento de fêmeas de corte, com um ano de idade, a suplementação energética para bezerras mantidas em pastagem cultivada de inverno aumentou significativamente a ocorrência de estros. Animais suplementados com $0,7 \%$ e $1,4 \%$ do PV/dia apresentaram $54,9 \%$ e $75,8 \%$ mais estros que os nãosuplementados. O percentual médio de estro observado para bezerras do mesmo rebanho, com maior peso vivo por ocasião da entrada na pastagem de inverno, foi de 49,5\% aos 12 meses de idade (Frizzo et al., 2003).

A importância do ganho diário médio, em uma fase específica do ciclo, indica pouca flexibilidade na programação alimentar para acasalamentos de fêmeas de corte aos 18 meses de idade. O alto desempenho individual exigido durante o inverno, período em que a pastagem natural tem seu crescimento paralisado, indica que deve ser providenciada alimentação suplementar que assegure ganhos superiores a $0,576 \mathrm{~kg} / \mathrm{dia}$. Ao reunir os dois fatores determinantes do aparecimento de estro, alto desempenho individual no primeiro inverno e peso superior a $295 \mathrm{~kg}$, no período de acasalamento, surge outro parâmetro a ser considerado, o peso no início do inverno. Alto desempenho no inverno, sem peso inicial adequado, impede que seja atingido o peso exigido para aparecimento de estro, na estação de acasalamento.

\section{R. Bras. Zootec., v.33, n.6, p.2123-2131, 2004 (Supl. 2)}

Tabela 3 - Médias estimadas de peso, condição corporal e ganho de peso de novilhas que apresentaram ou não apresentaram estro aos 20 meses de idade

Table 3 - Least square means of liveweight, body condition and average daily gain of heifers with or without heat at 20 months of age

\begin{tabular}{|c|c|c|}
\hline \multirow[b]{2}{*}{$\begin{array}{l}\text { Data } \\
\text { Date }\end{array}$} & $\begin{array}{c}\text { Estro } \\
\text { With heat }\end{array}$ & $\begin{array}{c}\text { Sem estro } \\
\text { Without heat }\end{array}$ \\
\hline & \multicolumn{2}{|c|}{$\begin{array}{c}\text { Peso, } \mathrm{kg} \\
\text { Liveweight, } \mathrm{kg}\end{array}$} \\
\hline $08 / 11 / 2001$ & 244,5 & 257,8 \\
\hline $25 / 12 / 2001$ & 257,8 & 241,3 \\
\hline $13 / 04 / 2002$ & $321,9 *$ & 294,8 \\
\hline \multirow[t]{2}{*}{ 01/06/2002 } & $323,1 *$ & 281,4 \\
\hline & \multicolumn{2}{|c|}{$\begin{array}{c}\text { Condição corporal (1-5) } \\
\text { Body condition (1-5) }\end{array}$} \\
\hline 08/11/2001 & 3,46 & 3,30 \\
\hline 25/12/2001 & 3,04 & 3,03 \\
\hline 13/04/2002 & 3,32 & 3,16 \\
\hline \multirow[t]{2}{*}{ 01/06/2002 } & 2,93 & 2,72 \\
\hline & \multicolumn{2}{|c|}{$\begin{array}{l}\text { Ganho médio diário, kg/d } \\
\text { Average daily gain, } \mathrm{kg} / \mathrm{d}\end{array}$} \\
\hline 01/07-08/11/2001 & $0,770 *$ & 0,576 \\
\hline $09 / 11-25 / 12 / 2001$ & $-0,045$ & $-0,161$ \\
\hline $26 / 12 / 2001-13 / 04 / 2002$ & 0,577 & 0,506 \\
\hline 14/04-01/06/2002 & $-0,123$ & $-0,199$ \\
\hline
\end{tabular}

${ }^{*} \mathrm{~F}$ significativo a $5 \%$ (Significant at $5 \%$ ).

O ECC não foi diferente $(\mathrm{P}>0,05)$ entre novilhas que apresentaram e que não apresentaram estro. Semmelmann et al. (2001) observaram, em novilhas Nelore acasaladas aos 18 meses, que o ECC das novilhas prenhas foi, em média, 0,11 superior ao das novilhas falhadas. No sistema 'um ano' de acasalamento, o ECC das novilhas não gestantes foi inferior ao ECC das novilhas prenhas $(\mathrm{P}<0,01)$, da desmama ao final do acasalamento (Rocha \& Lobato, 2002b).

Na Tabela 4, é apresentado o percentual de ovários funcionais em 09/11/2001 e 01/06/2002, nos diferentes sistemas.

A funcionalidade dos ovários, no primeiro e segundo invernos, mostrou relação distinta com o uso de suplementos (Tabela 4). No primeiro inverno, novilhas suplementadas apresentaram maior funcionalidade dos ovários $(\mathrm{P}<0,05)$. Estes animais, quando mantidos exclusivamente em pastagem nativa no verão e outono subseqüentes, tiveram desempenho inferior aos animais dos demais sistemas, que conservaram alto nível alimentar. Em novilhas Hereford e Aberdeen Angus, aos 14 meses de idade, 
Tabela 4 - Percentual de novilhas de corte com ovário funcional em 09/11/2001 e 01/06/2002, submetidas a diferentes sistemas de alimentação

Table 4 - Percentage of beef heifers with functional ovary at 11/09/2001 and 06/01/2002 submitted at different feeding systems

\begin{tabular}{lc}
\hline Data e tratamento & Com atividade \\
Date and treatment & Activity
\end{tabular}

\section{9/11/2001}

Aveia + azevém

$18 \mathrm{~b}$

Black oat + Annual ryegrass

Aveia + azevém + suplementação

$50 \mathrm{a}$

Black oat + Annual ryegrass + supplementation

01/06/2002

Aveia + azevém + milheto

Black oat + Annual ryegrass + pearl

millet pasture

Aveia + azevém + campo

$33 a b$

Black oat + Annual ryegrass pasture +

natural pasture

Aveia + azevém + suplementação + milheto

$45 \mathrm{ab}$

Black oat + Annual ryegrass + supplementation

+ pearl millet pasture

Aveia + azevém + suplementação + campo

Black oat + Annual ryegrass +

supplementation + natural pasture

a,b Valores seguidos de letras distintas na mesma coluna diferem pelo teste de aleatorização $(P=0,08)$.

$a, b$ Values followed of distinct letters in same column are different by randomization test $(P=.08)$.

Beretta \& Lobato (1998) observaram 25\% de fêmeas ciclando. Segundo esses autores, as novilhas com atividade cíclica apresentavam peso médio de $254 \mathrm{~kg}$ e ECC de 3,1, enquanto as que não ciclavam, peso médio de 206 kg e ECC de 2,6. Para novilhas com peso médio variando entre 280 e $325 \mathrm{~kg}$. Pereira Netto \& Lobato (1998) observaram 60\% das novilhas apresentando atividade ovariana aos 24 meses de idade. No presente trabalho, $34 \%$ das novilhas, em média, apresentaram ovários funcionais ao final do primeiro inverno, com um ano de idade. Aos 18/20 meses, este valor aumentou para $44 \%$, na média dos quatro sistemas. Considerando que todas estas novilhas ficassem prenhas, este percentual seria inferior à taxa de natalidade média observada no rebanho de cria no estado (50\%). Entre os sistemas alimentares estudados, o único que assegurou um percentual de ovários funcionais superior a esta média, 72\%, foi o que utilizou 'aveia + azevém + milheto'. Em razão de o milheto ser uma espécie anual de estação quente, seu adequado estabelecimento está associado às condições climáticas da estação e, nesta região, neste período, as estiagens são freqüentes. Isto eleva o risco de que os animais permaneçam no campo nativo por um período maior e não atinjam desenvolvimento adequado para acasalamento aos 18/20 meses de idade. A economicidade do empreendimento seria bastante comprometida, neste caso, pois as despesas com fertilizantes e sementes, neste período especificamente, seriam desnecessárias, caso a idade prevista para acasalamento destes animais fosse aos 24 meses. O risco seria menor com a utilização de forrageiras perenes de estação quente, mas dados biológicos locais sobre o desempenho de novilhas de corte para acasalamento aos 18/20 meses de idade, nestas espécies, são inexistentes.

\section{Conclusões}

O ganho individual ao primeiro inverno e o peso corporal aos 18 meses constituem fatores determinantes para que novilhas de corte entrem em fase reprodutiva aos 18/20 meses de idade.

A manifestação de estro aos 18/20 meses de idade, em novilhas de corte, está diretamente relacionada à utilização de pastagem cultivada e de suplementação no primeiro inverno pós-desmama.

Quando o objetivo é acasalamento de novilhas de corte aos 18/20 meses de idade, a utilização exclusiva de pastagem natural no verão/outono após o primeiro inverno é insuficiente para assegurar desenvolvimento adequado a estes animais.

\section{Literatura Citada}

ALBUQUERQUE, L.G.; FRIES, L.A. Precocidade: Estratégia de seleção. In: SIMPÓSIO: O NELORE DO SÉCULO XXI - NELORE PRECOCE: SELEÇÃO, PRODUÇÃO E COMERCIALIZAÇÃO, 4., 1997, Uberaba. Anais... Uberaba: ABCZ-ACNB, 1997. p.164-179.

ASSOCIATION OF OFFICIAL ANALYTICAL CHEMISTS AOAC. Official methods of analysis. 14.ed. Washington, D.C.: 1984. 1141p.

ALLDEN, W.G. Energy and protein suplementation for grazing livestock. In: MORLEY, F.H.W. (Ed.) Grazing animals. Amsterdan: Elsevier, 1981. p.259-308.

ANUALPEC. Anuário estatístico da pecuária brasileira. Ed. Argos Comunicação, 2002. 400p.

BERETTA, V.; LOBATO, J.F.P. Efeitos da ordem de utilização de pastagens melhoradas no ganho de peso e desempenho reprodutivo de novilhas de corte. Revista Brasileira de Zootecnia, v.25, n.1, p.46-57, 1996.

BERETTA, V.; LOBATO, J.F.P. Sistema ‘um ano’ de produção de carne: avaliação de estratégias alternativas de alimentação 
hibernal para novilhas de reposição. Revista Brasileira de Zootecnia, v.27, n.1, p.157-163, 1998.

EUCLIDES, V.P.B.; MACEDO, M.C.M.; OLIVEIRA, M.P. Avaliação de diferentes métodos de amostragem sob pastejo. Revista Brasileira de Zootecnia, v.21, n.4, p.691-702, 1992.

FOX, D.G.; SNIFFEN, C.J.; O’CONNOR, J.D. Adjusting nutrient requirements of beef cattle for animal and environmental variations. Journal of Animal Science, v.66, n.6, p.475495, 1988.

FRIZZO, A.; ROCHA, M.G.; RESTLE, J. et al. Suplementação energética na recria de corte em pastagem de inverno. Revista Brasileira de Zootecnia, v.27, n.3, p.157-163, 2003.

GARDNER, A.L. Técnicas de pesquisa em pastagem e aplicabilidade de resultados em sistemas de produção. Brasília:IICA/EMBRAPA-CNPGL, 197p. (Série publicações miscelâneas, 634). 1986.

HILL, I.D. A resposta do gado Nelore à seleção. In: SIMPÓSIO: O NELORE DO SÉCULO XXI, 3., 1995, Ribeirão Preto. Anais... Ribeirão Preto: ACNB, 1995. p.49-61.

LANNA, D.P. Fatores condicionantes e predisponentes da puberdade e da idade de abate. In: SIMPÓSIO SOBRE PECUARIA DE CORTE, 4., 1997. Piracicaba, SP. Anais...Piracicaba, 1997. p.161-204.

LOWMAN, B.G.; SCOTT, N.; SOMERVILLE, S. Condition scoring beef cattle. Edinburgh: East of Scotland College of Agriculture, 1976. 8p. (Bulletin 6).

MOOJEN, E.L.; MARASCHIN, G.E. Potencial produtivo de uma pastagem nativa do Rio Grande do Sul submetida a níveis de oferta de forragem. Ciência Rural, v.32, n.1, p.60-65, 2002.

MORAES, A.; MARASCHIN, G.E. Pressões de pastejo e produção animal em milheto cv. Comum. Pesquisa Agropecuária Brasileira, v.23, n.2, p.197-205, 1988.

MORENO, J.A. Clima do Rio Grande do Sul. Porto Alegre: Secretaria da Agricultura, 1961. 41p.

NOLLER, C.R. Nutritional requirements of the grazing animal. In: SIMPÓSIO INTERNACIONAL SOBRE PRODUÇÃO ANIMAL EM PASTEJO, 1997, Viçosa, MG. Anais...Viçosa, MG: Universidade Federal de Viçosa, 1997. p.145-172.

NATIONAL RESEARCH COUNCIL - NRC. Nutrient requirement of beef cattle. 6.ed. Washington, D.C.: National Academy Press, 1984. 90p.
PEREIRA NETO, O.A.; LOBATO, J.F.P. Efeitos da ordem de utilização de pastagens nativas melhoradas no desenvolvimento e comportamento reprodutivo de novilhas de corte. Revista Brasileira de Zootecnia, v.27, n.1, p.60-65, 1998.

RESTLE, J.; POLLI, V.A.; SENNA, D.B. Efeito de grupo genético e heterose na idade à puberdade e desempenho reprodutivo de novilhas de corte. Pesquisa Agropecuária Brasileira, v.34, n.4, p.701-707, 1999.

RICE, L.E. Nutrition and the development of replacement heifers. Veterinary Clinics of North America. Food Animal Practice, v.7, n.1, p.27-42, 1991.

ROCHA, M.G.; LOBATO, J.F.P. Sistemas de alimentação pósdesmama de bezerras de corte para acasalamento com 14/15 meses de idade. Revista Brasileira de Zootecnia, v.31, n.4, p.835-843, 2002a.

ROCHA, M.G.; LOBATO, J.F.P. Avaliação do desempenho reprodutivo de novilhas de corte primíparas aos dois anos de idade. Revista Brasileira de Zootecnia, v.31, n.3, p.13881395, 2002b.

STATISTICAL ANALYSIS SYSTEM - SAS. User's guide. v.6.08. 3. ed. Cary, N.C.: SAS Institute Inc, 1996.

SEMMELMANN, C.E.N.; LOBATO, J.F.P.; ROCHA, M.G. Efeito de sistemas de alimentação no ganho de peso e desempenho reprodutivo de novilhas Nelore acasaladas aos 17/18 meses. Revista Brasileira de Zootecnia, v.30, n.3, p.835-843, 2001.

SHORT, R.E.; BELLOWS, R.A. Relationship among weight gains, age at puberty and reproductive performance in heifers. Journal of Animal Science, v.32, n.5, p.1964-1970, 1971.

STEEL, R.G.D.; TORRIE, J.H. Bioestadística: princípios y procedimentos. México: Mc Graw-Hill, 1980. 662p.

TILLEY, J.M.A.; TERRY, R.A. A two-stage technique for the in vitro digestion of forage crop. Journal of Bristish Grassland Society, v.18, n.2, p.104-111, 1963. 